PACS: 05.70. Ln; 61.72.jd. 61.72 Qq, 62.20.fg.81.30.30.Kf

\title{
ON THE PROBLEM OF MARTENSITE TETRAGONALITY NATURE
}

\author{
I.N. Laptev ${ }^{1}$, O.O. Parkhomenko ${ }^{1,2}$ \\ ${ }^{1}$ National Scientific Center "Kharkiv Institute of Physics and Technology" \\ 1, Akademicheskaia St., Kharkov, 61108, Ukraine \\ ${ }^{2}$ V.N. Karazin Kharkov National University \\ 4 Svobody Sq., Kharkov, 61022, Ukraine \\ e-mail:parkhomenko@kipt.kharkov.ua \\ Received August 11, 2017
}

Despite the fact that scientists have been studying the nature of the mechanism of martensite formation for almost a hundred years, these studies remain, still, relevant. In this paper, the authors present two new results related to the classical question of the role of carbon in martensite formation. If, while dissolving in the lattice, the carbon is located in the center of the octahedral emptiness, then under the influence of stresses caused by quenching or deformation, in martensite it is displaced into one of the pyramids of the constituent octahedra. The fact of the independence of the specific atomic volume of phase mismatch during martensitic transformation of iron from the carbon content was found. This fact indicates that the tetragonality of carbon steels is a function not so much of carbon as vacancies. In the pure iron the "vacancy" tetragonality can vary from 1.03 to 1.06 .

KEY WORDS: martensite transformation, stress state, tetragonality, vacancies, iron, carbon

\author{
К ВОПРОСУ О ПРИРОДЕ ТЕТРАГОНАЛЬНОСТИ МАРТЕНСИТА \\ И.Н. Лаптев ${ }^{1}$, А.А. Пархоменко ${ }^{1,2}$ \\ ${ }^{1}$ Национальний научный центр «Харьковский физико-технический институт» \\ ул. Академическая 1, г. Харьков 61108, Украина \\ ${ }^{2}$ Харьковский национальный университет имени В.Н. Каразина \\ пл. Свободы 4, г. Харьков, 61022, Украина
}

Несмотря на то, что описанием природы механизма мартенситообразования ученые занимаются уже почти сто лет, эти исследования остаются, по-прежнему, актуальными. В данной работе авторы представляют два новых результата, связанные с классическим вопросом о роли углерода в МП. Если, растворяясь в решетке, углерод располагается в центре октаэдрической пустоты, то под действием напряжений, вызванных закалкой или деформацией, в мартенсите он оказывается смещенным в одну из пирамид составляющих октаэдр. Впервые обнаружен факт независимости удельного атомного объема фазового несоответствия при мартенситном превращении железа от содержания углерода. Этот факт свидетельствует о том, что тетрагональность углеродистых сталей есть функция не столько углерода сколько вакансий. В чистом железе «вакансионная» тетрагональность может меняться в пределах от 1,06 до 1,03.

КЛЮЧЕВЫЕ СЛОВА: мартенситные превращения, напряженное состояние, тетрагональность, вакансии, железо, углерод

\section{ЩОДО ПИТАННЯ ПРИРОДИ ТЕТРАГОНАЛЬНОСТІ МАРТЕНСИТУ I.М. Лаптєв ${ }^{1}$, О.О. Пархоменко ${ }^{1,2}$ \\ ${ }^{1}$ Національний науковий центр «Харківський фізико-технічний інститут» вул. Академична 1, м. Харків 61108, Украӥна \\ ${ }^{2}$ Харківський наиіональний університет імені В.Н. Каразіна пл. Свободи 4, м. Харків, 61022, Украӥна}

Не дивлячись на те, що вивченням природи мартенситоутворення вчені займаються вже майже сто років, ці дослідження залишаються як і раніше актуальними. В цій роботі автори представляють два нових результати , які пов'язані 3 класичним питанням щодо ролі вуглецю у у мартенситних перетвореннях. Якщо у твердому розчині кристалічної гратки вуглець знаходиться у центрі октоедрічної пустоти, то під впливом напружень, що викликані гартуванням або деформацією, у мартенситі він зміщується у бік одної з пірамід, що створюють октаедр. У роботі вперше показана незалежність питомого атомного об' єму фазової невідповідності заліза при мартенситних перетвореннях від вмісту вуглецю. Цей факт свідчить, що тетрагональність вуглецевих сталей є функцією не тільки вуглецю, але передусім-вакансій. У чистому залізі « вакансій на » тетрагональність може змінюватись у межах від 1,03 до 1,06.

КЛЮЧОВІ СЛОВА: мартенситні перетворення, напружений стан, тетрагональність, вакансії, залізо, вуглець

Несмотря на то, что изучением природы мартенсита ученые занимаются уже почти сто лет, вопрос о механизмах его образования и роли тетрагональности кристаллической решетки остается до конца не выясненным. В контексте данной работы, под тетрагональностью авторы понимают собственную упругую деформацию ГЦК - решетки, при ее превращении в ОЦК-структуру. Такие деформации могут создаваться сдвигом под действием механических или термических напряжений, легирования определенным элементным составом или примесями.

Эти представления о природе образования мартенсита находятся в согласии с давно забытой «релаксационной моделью» С.С. Штейнберга [1]. Подобные взгляды на природу мартенситообразования высказывали в свое время А.П. Гуляев [2], а из наших современников следует назвать С.П. Ошкадерова [3].

Уже давно открыты мартенситы в различных металах и сплавах, которые можно разделить на мартенситы 
«внедрения» и мартенситы «замещения» [4]. Считается, что в углеродистых сталях за образование мартенсита отвечает углерод [5], хотя вопрос о его расположении в решетке железа до сих пор остается открытым.

Целью работы был анализ накопленных за десятилетия экспериментальных данных по изменению решеток феррита, аустенита и мартенсита в зависимости от содержания углерода, при формировании им тетрагональных искажений в железе.

\section{АНАЛИЗ ЭКСПЕРИМЕНТАЛЬНЫХ ДАННЫХ}

Наши представления о мартенсите связаны с вопросом упорядочения углерода. Мы привыкли считать, что при закалке аустенита углерод изменяет свое положение и в мартенсите он оказывается расположенным в центре ребра ОЦТ ячейки. Но ведь это положение было и есть центр октаэдра. И в аустените, и феррите углерод, растворяясь, тоже находится в центре октаэдра. Если это так, то не понятно, о каком упорядочении при образовании мартенсита идет речь. И в аустените и в феррите центр любого октаэдра одновременно принадлежит шести объемно центрированным ячейкам ортогонально ориентированным попарно. Более того, все три структуры (аустенит, феррит и мартенсит) могут быть составлены из одних октаэдров с различным соотношением диагоналей, которое изменяется в тех же пропорциях, что и тетрагональность в ОЦК и ГЦК решетках (от 1 до 1,4142). Из этого следует, что углероду, если он находится в центре октаэдра, не надо перестраиваться для образования мартенсита.

Анализ экспериментальных данных по изменению параметров решеток феррита, аустенита и мартенсита [2] и объемов элементарных ячеек этих структур, которые представлены в таблице, позволяет сделать очень важный вывод о расположении углерода в решетке железа.

Как следует из таблицы, параметр «с» возрастает прямо пропорционально росту содержания углерода в мартенсите. В тоже время, параметр «а» мартенсита слабо зависит от содержания углерода и уменьшается от $2,861 \AA$ в феррите до $2,843 \AA$ в мартенсите с 1,6 вес.\% С, и с дальнейшим повышением концентрации углерода вообще остается неизменным. Иначе говоря, прямая пропорциональность с изменением содержания углерода для параметра «а», как это принято считать [6-10], не соблюдается.

Таблица

Изменения параметров кристаллических решеток феррита $\left(\mathrm{a}_{\mathrm{m}}\right.$, при $\left.\mathrm{C}_{\mathrm{c}}=0\right)$, мартенсита $\left(\mathrm{a}_{\mathrm{M}}\right.$ и $\left.\mathrm{c}_{\mathrm{m}}\right)$, аустенита $\left(\mathrm{a}_{\gamma}\right)$, их объемов $\left(\mathrm{V}_{\alpha}, \mathrm{V}_{\mathrm{M}}, \mathrm{V}_{\gamma}\right)$, тетрагональности (c/a), объема фазового несоответствия $(\Delta \mathrm{V})$ и его относительное изменение $\left(\Delta \mathrm{V} / \mathrm{V}_{\mathrm{M}}\right)$ в зависимости от содержания углерода $\left(\mathrm{C}_{\mathrm{c}}\right)$ в железе (по данным монографии [2]).

\begin{tabular}{|l|l|l|l|l|l|l|l|l|}
\hline $\begin{array}{l}\mathrm{C}_{\mathrm{c}}, \\
\text { вес. } \%\end{array}$ & $\mathrm{a}_{\gamma}, \AA$ & $\begin{array}{l}0,5 \mathrm{~V}_{\gamma}, \\
\AA^{3}\end{array}$ & $\mathrm{a}_{\mathrm{M}}, \AA$ & $\mathrm{c}_{\mathrm{M}}, \AA$ & $\mathrm{V}_{\mathrm{M}}, \AA^{3}$ & $\mathrm{c} / \mathrm{a}$ & $\begin{array}{l}\Delta \mathrm{V}^{3} \mathrm{~V}_{\mathrm{M}}- \\
0,5 \mathrm{~V}_{\gamma}, \AA^{3}\end{array}$ & $\Delta \mathrm{V} / \mathrm{V}_{\mathrm{M}}, \%$ \\
\hline 0,0 & 3,546 & 22,31 & 2,86 & 2,86 & 23,40 & 1 & 1,09 & 4,65 \\
\hline 0,2 & 3,555 & 22,483 & 2,857 & 2.882 & 23,55 & 1,009 & 1,07 & 4,54 \\
\hline 0,4 & 3,564 & 22,656 & 2,853 & 2,909 & 23,68 & 1,018 & 1,024 & 4,32 \\
\hline 0,6 & 3,573 & 22,829 & 2,851 & 2,931 & 23,83 & 1,027 & 1,01 & 4,24 \\
\hline 0,8 & 3,582 & 23,002 & 2,849 & 2,957 & 24,01 & 1,036 & 1,008 & 4,20 \\
\hline 1,0 & 3,591 & 23,175 & 2,847 & 2,982 & 24,19 & 1,045 & 1,015 & 4,20 \\
\hline 1,2 & 3,600 & 23,328 & 2,845 & 3,002 & 24,30 & 1,054 & 0,98 & 4,16 \\
\hline 1,4 & 3,609 & 23,521 & 2,844 & 3,03 & 24,52 & 1,063 & 0,999 & 4,07 \\
\hline 1,6 & 3,618 & 23,694 & 2,843 & 3,053 & 24,70 & 1,072 & 1,006 & 4,07 \\
\hline 1,8 & 3,627 & 23,867 & 2,843 & 3,075 & 24,88 & 1,081 & 1,013 & 4,07 \\
\hline Среднее \\
\hline
\end{tabular}

\section{ПРЕДЛАГАЕМАЯ МОДЕЛЬ}

Если принять, что углерод в ОЦТ ячейке мартенсита располагается не в центре октаэдра (в этом положении он бы изменил параметр «а» только однажды), а в пирамиде (рис.1,2). Только в таком случае с ростом параметра «с» влияние углерода на параметр «а» будет уменьшаться, а сам параметр «а» будет сокращаться. Собственно это и есть деформация Бейна.

В таком случае, процесс упорядочения при образовании мартенсита заключается в том, что распределенный в аустените по октаэдрам углерод смещается и занимает одинаково ориентированные пирамиды в октаэдрических ячейках.

По-видимому, именно эти положения (1/3 высоты пирамиды) определяются как «тяжи» на электроннограммах в сталях и сплавах, которые оказываются в, так называемых, «прекурсорных» или предмартенситных состояниях [11].

Чтобы углерод оказался смещенным в пирамиду на него должны действовать выталкивающие силы, которые могут быть либо постоянны, либо возрастать с ростом содержания углерода в железе. Тогда, в первом случае, реализовалась бы модель «универсальной тетрагональности», обусловленной только внедренным углеродом, которую предлагают авторы [12]. В такой модели, экспериментально измеряемая тетрагональность 
мартенсита представляет собой усредненную по объему величину от единственной «универсальной», образованной углеродом, внедренным в ячейку железа. Во втором, тетрагональность - усредненная величина по спектру различных значений, обусловленных различным содержанием и расположением углерода в ячейке железа, а точнее - в пирамиде.
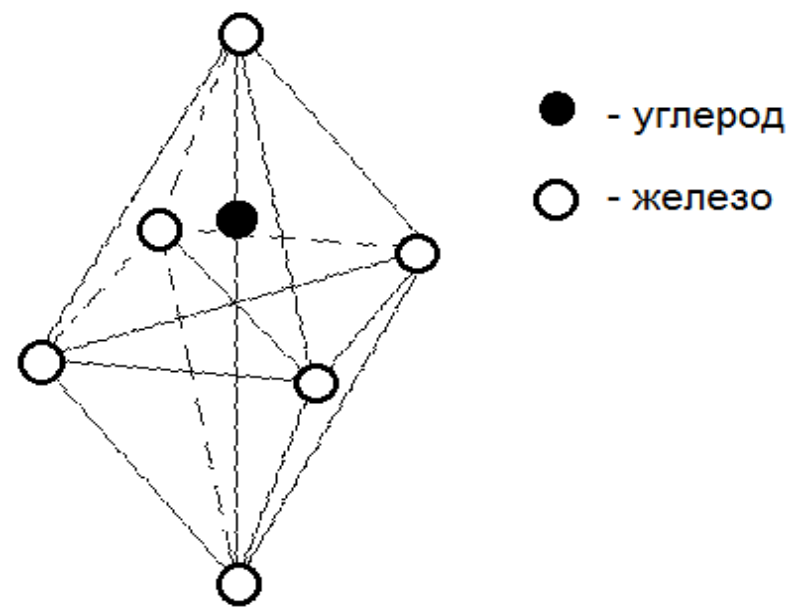

Рис.1. Наиболее вероятное положение углерода в октаэдрической поре мартенсита.

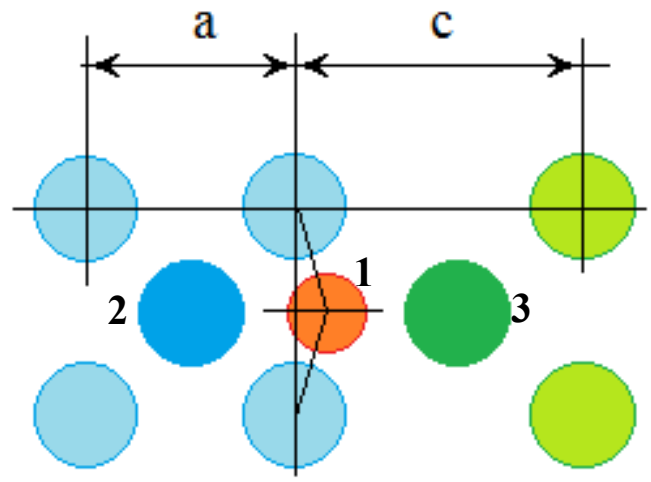

Рис.2. Формирование ОЦТ структуры в ОЦК железе.

Показано смещение атома углерода (поз.1) в октаэдрической поре ячейки железа. Плоскость рисунка соответствует плоскости (100) ОЦК структуры. Позиции 2 и 3 соответствуют центральным атомам ОЦК и ОЦТ ячеек и, следовательно, расположены над базисом. В одной с ними плоскости находится и углерод.

Эти представления и имеющиеся экспериментальные данные позволяют легко рассчитать ту тетрагональность мартенсита, которая может быть обусловлена только внедренным углеродом. Выполняя расчеты, для первого случая, мы вместо силы, выталкивающей углерод из центра октаэдра, использовали диаметр атома железа равный параметру его ОЦК решетки.

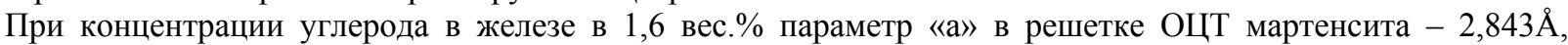

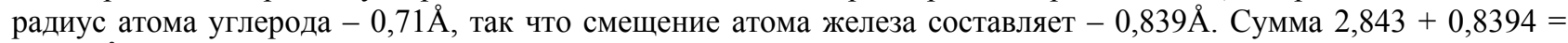
$3,6824 \AA$ равна параметру «с», а отношение с/a $=1,2953$ определит тетрагональность одной ячейки с одним атомом углерода. Углерод имеет ограниченную растворимость в железе. В аустените при $1148^{\circ} \mathrm{C}$ его содержание не может быть больше, чем 2,14 вес.\%. При закалке даже с максимальным содержанием его в твердом растворе он не заполняет все октаэдрические пустоты и, по нашим оценкам, влияние одного внедренного атома углерода распространяется приблизительно на четыре - пять ближайших ячеек.

Считая, что атом углерода находится на общей для четырех ячеек оси «с» можно рассчитать усредненное значение их тетрагональности, например, для содержания углерода в железе равном 1,6 вес.\%: $(1,2953 \times 1+1 \times 3) / 4=1,0738$, что находится в хорошем соответствии со значением тетрагональности, определенным экспериментально (см. таблицу - 1,072).

Оценивая параметр «с» мы не учитывали сжимающего влияния окружающей матрицы, что, безусловно, будет его уменьшать. Однако и без учета этой деформации простейшие вычисления показывают, насколько точно, предлагаемая модель, определяет положение атома углерода в решетке мартенсита.

Однако все не так просто. На самом деле не углерод определяет тетрагональность, а тетрагональность, заданная, например, уровнем термических напряжений, возникающих в процессе закалки, определяет положение углерода в ячейке железа. 
Реально диаметр атома железа чуть больше $2 \AA$. . Такого же размера достигает и кратчайшее межатомное расстояние в центральной плоскости октаэдра. Это значит, что атом углерода (диаметр 1,4 $\AA$ ) способен свободно разместиться в октаэрическом междоузлии. По-видимому, в аустените (температура, от которой ведется закалка, выше $900^{\circ} \mathrm{C}$ ) он действительно располагается в центре октаэдра. Но в процессе закалки в структуре возникают градиенты термических напряжений, которые с одной стороны, порождают тетрагональные искажения решетки [13], а с другой, заставляют углерод смещаться в направлении действия градиента растяжений, занимая определенные положения в пирамиде.

Из этого следует, что углерод не является причиной образования тетрагональности в железе. С ростом содержания углерода в железе напряжения необходимые для его смещения возрастают, что ведет к подавлению процесса образования мартенсита. Этим объясняется существование остаточного аустенита и рост его массы с ростом содержания углерода (углерод - аустенитобразующий элемент).

Предлагаемая модель (рис.1,2) позволила нам правильно определить положение атома углерода в ячейке железа и утверждать теперь, что никакого универсального значения тетрагональности углерод в железе не создает. Просто в процессе закалки с ростом его содержания в железе возрастают термические напряжения (чем выше концентрация углерода, тем большее сопротивление он оказывает мартенситному превращению, поэтому температура начала образования мартенсита снижается), что приводит к росту тетрагональности системы «железо-углерод-вакансии» и большим смещениям углерода вдоль оси «с». Как следует из таблицы, углерод, в обособившемся кристалле мартенсита, способен поддерживать тетрагональность порядка 1,081 при концентрации его в железе около 1,8 об.\%. При большем содержании углерода сталь должна оставаться аустенитной.

Таким образом, полученные результаты в корне меняют наши представления о месте размещения углерода в ОЦТ ячейке железа и о роли его в образовании мартенсита в сталях.

Из таблицы следует еще один удивительный факт: не смотря на то, что с ростом содержания углерода в твердом растворе и, при этом, ростом, как фазового объема аустенита, так и мартенсита, разность этих объемов (объем фазового несоответствия) остается постоянной. Действительно, как видно из таблицы, изменение величины $\Delta \mathrm{V}$ не превышает долей кубического ангстрема на фоне объема мартенсита составляющего несколько десятков кубических ангстрем. Поскольку экспериментальные данные получены на закаленных сталях, то не вызывает сомнений, что объем фазового несоответствия никак не связан с углеродом, а обусловлен только вакансиями.

Подтверждением правильности вывода могут являться результаты экспериментальной работы [14]. Проведенная закалка чистого железа (содержание углерода 0,0015 вес.\%) привела к образованию мартенсита, масса которого росла с ростом скорости закалки и достигала 100\%. Без сомнения, при таком ничтожном содержании углерода он не может оказывать влияние на образование тетрагональности (если бы он был ответственным за ее образование) во всем объеме закаливаемого кристалла. Единственный «элемент» способный породить тетрагональность в объеме - вакансии.

Метод Фазовых Диаграмм Мартенситных Превращений (ФДМП) позволяет оценить «вакансионную» тетрагональность, которая может возникать в чистом железе, например, при различных скоростях закалки. В зависимости от температуры начала образования мартенсита $\mathrm{M}_{\mathrm{s}}$ тетрагональность обособившегося мартенсита может изменяться в пределах от 1 до 1,05 , сначала возрастая с ростом скорости охлаждения (от $\mathrm{M}_{\mathrm{s}}$ ниже $900^{\circ} \mathrm{C}$ до $\left.\mathrm{M}_{\mathrm{s}}=545^{\circ} \mathrm{C}\right)$, а затем понижаясь [13].

Из этого следует, что тетрагональность мартенсита является функцией не столько углерода (а в сталях, не содержащих углерод, это, без сомнения) сколько вакансий. Именно поэтому объем фазового несоответствия не меняется с изменением концентрации углерода (разумеется, при постоянной скорости охлаждения).

Любой дефект кристаллической решетки, обусловливающий появление поля внутренних деформаций с симметрией отличной от симметрии решетки, является источником внутреннего трения. Поэтому метод внутреннего трения является эффективным методом идентификации тетрагональных искажений. Если следовать [15], то одиночные вакансии не являются источником внутреннего трения, т.к. не нарушают симметрии кристалла. Тетрагональные искажения в решетке кристалла могут создавать только комплексы вакансий, начиная от дивакансий.

Исследования внутреннего трения в образцах сплава Fe-Al [16] подвергнутых $\gamma$-облучению $\left(\mathrm{Co}^{60}\right.$, энергия $\gamma$-квантов порядка 1,25 МэВ) обнаружили рядом с углеродным пиком Снука, дополнительный X (или R) пик, появление которого однозначно связано с образованием вакансий в сплаве.

Чтобы понять, каким образом в данном случае вакансии нарушают симметрию поля кристалла и создают тетрагональные искажения в нем, достаточно представить, что вакансия не образуется как точечный дефект, а создает комплекс, например, «углерод-вакансия», «алюминий-вакансия» либо просто - «собственный межузельный атом-вакансия». Поскольку пики разнесены, а пик Снука точно связан с углеродом, то, надо полагать, что пик $\mathrm{X}$ обусловлен образованием комплексов «алюминий-вакансия». Геометрически такой комплекс следует представлять как одновременное нахождение вблизи одного узла и атома и вакансии, либо просто смещенный из узла, но не покинувший свою ячейку, атом. При этом вакансия не является точечным дефектом, а представляет собой объемную деформацию растяжения. Под действием внутренних или 
приложенных извне напряжений такие комплексы могут быть ориентированны в одном направлении. Объединяясь в конгломераты в волнах концентрационных неоднородностей, они будут создавать тетрагонально искаженные области кристалла (когерентные зоны предвыделений), которые, по сути, являются мартенситом [13].

Образование таких комплексов на собственных атомах, атомах внедрения и замещения обусловлено разной энергией их образования, что, в свою очередь, определяет различие температур начала и конца обособления мартенсита в сталях и сплавах.

И последнее. Рентгенографически мы все же определяем некую усредненную тетрагональность мартенсита. Однако этот спектр тетрагональностей не связан с существованием ее «универсального» значения, образуемого атомом углерода в одной ячейке железа. Такой тетрагональности не существует. Спектр возникает потому, что углерод в сталях распределяется неоднородно. Именно неоднородности его распределения и определяют разброс тетрагональностей.

\section{ВЫВОДЫ}

1) Характер изменения параметров ОЦТ решетки мартенсита указывает на то, что углерод, в мартенсите углеродистых сталей, располагается не в центре октаэдра, как это принято считать, а смещается в одну из пирамид, составляющих октаэдр.

2) Углерод не создает тетрагональность в железе. Наоборот, он тормозит ее развитие, что прямо следует из факта снижения температуры начала образования мартенсита, но в обособившемся мартенсите, он является стопором (и тем более мощным, чем выше его содержание в стали), который не позволяет системе после обособления полностью релаксировать внутренние напряжения и избавиться от тетрагональности.

3) Экспериментально измеряемая тетрагональность мартенсита углеродистых сталей - это усредненная по объему кристалла величина, которая не связана с существованием «универсальной» тетрагональности, а обусловлена только неоднородностью распределения углерода в железе.

4) Впервые обнаружен факт независимости объема фазового несоответствия при мартенситном превращении железа.

5) Неизменный объем фазового несоответствия при одинаковой скорости охлаждения, определяемый как разность объемов ОЦТ ячеек мартенсита и аустенита, свидетельствует о том, что тетрагональность углеродистых сталей есть функция не столько углерода, сколько вакансий (а вернее, деформаций и напряжений, которые они порождают в неравновесных системах). В чистом железе в обособившихся кристаллах мартенсита «вакансионная» тетрагональность может меняться в пределах от 1 до 1,05.

\section{СПИСОК ЛИТЕРАТУРЫ}

1. Schteinberg S.S. Relaxation phenomenas in martensite // Journal of technical physics - 1935. - Vol. 5. - No. $2 .-$ P. 362 - 373.

2. Guliaev A.P. Metall Science. - M.: Oborongiz, 1963. - 185p. (In Russian)

3. Oshkaderov S.P. Phase transformation in austenite // Progress in Physics of Metals. - 2011. - Vol.12. - P.269-293. (In Russian)

4. Koval Yu.N., Lobodyuk V.A. Deformation and relaxation phenomenas during martensite transformation. - Kiev: Naukova Dumka, 2010. - 297p. (In Russian)

5. Meshkov Yu.Ya. On the problem on martensite tetragonality. // Proc. Int. Conf. "The modern problems of metal physics and physics of metallic systems" / Ed.IMF NANU, Kiev. - 25-27.05. - 2016. - P.22. (In Russian)

6. Kaminsky E.E., Percas M.D. Metal science problems. - M.: Metallurgiya, 1949. - 211p. (In Russian)

7. Arbuzov M.P. Metal physics and science problems. - Kiev: Academy of Sci. Edition. - 1955. - No. 6. - P. 3-11. (In Russian)

8. Kurdyumov G.V., The quenching and aging phenomenas in steel. - M.: Metallurgiya, 1960. - 140 p.

9. Kurdyumov G.V., Utevsky L.M., Entin R.I. Transformations in iron and steel. - M.: Nauka, 1977. - 238p. (In Russian)

10. Kurdyumov G.V., Lysak L.I. X-rays study of aging martensite // Journal of technical physics. - 1947. - Vol. 17. - P.525-531. (In Russian)

11. Lotkov. A.I, Baturin A.A. Martensite transformation in NiTi alloys // Physical mesomechanics. - 2011. - Vol.14. - No. 3. P. 69-84. (In Russian)

12. Lobodyuk V.A., Meshkov Yu.Ya. On the problem on martensite tetragonality in carbon steel // Metal physics and new technology. - 2017. - Vol.39. - P.122-130. (In Russian)

13. Laptev I.M., Parkhomenko O.O., Tkachenko V.I. The dualism of the vacancy nature in nonequilibrium systems // East European Journal of Physics. - 2016. - No.3. - P.113-120.

14. Morozov O.P., Mirzayev D.A., Schteinberg M.M. The speed quenching impact in iron // Metal physics and Metal science. 1987. - Vol. 32. - No. 6. - P. 1290 - 1297. (In Russian)

15. Damask A., Dins J. Point defects in metals. - M.: Mir, 1966. $-291 \mathrm{p}$

16. Rokhmanov N.Ya., Laptev I.N., Onishenko I.P., Parkhomenko O.O. Structural features of Fe-Al vacancy system // Functional Materials. - 2006. - Vol. 13. - No. 2. - P. 255-259. 